\title{
ESTRUTURA DA COMUNIDADE ÁRBOREA DE UM FRAGMENTO DE MATA CILIAR DO RIO TAQUARI, COLINAS, RIO GRANDE DO SUL
}

\author{
Marelise Teixeira ${ }^{1}$ \\ Aline Marjana Pavan ${ }^{2}$ \\ Luís Carlos Scherer ${ }^{3}$ \\ Gabriel Nicolini ${ }^{4}$ \\ Elisete Maria de Freitas ${ }^{5}$
}

\begin{abstract}
RESUMO
As matas ciliares são fundamentais na proteção de mananciais hídricos. O estudo objetivou conhecer a estrutura da comunidade arbórea de uma faixa de mata ciliar do Rio Taquari, no município de Colinas, Rio Grande do Sul. A amostragem foi realizada através da distribuição de 18 unidades amostrais (UA's) de $100 \mathrm{~m}^{2}$, a cada 20 metros, formando um transecto paralelo ao rio. Nas UA's foram amostrados os indivíduos com circunferência do caule à altura do peito igual ou superior a $20 \mathrm{~cm}$. Foram definidos os parâmetros de densidade, frequência e dominância, absolutas e relativas, e o índice de valor de importância (IVI). A diversidade foi estimada pelos índices de Shannon (H') e equabilidade de Pielou (J). Foram amostrados 415 indivíduos, 39 espécies e 21 famílias botânicas, sendo Fabaceae a família de maior riqueza. A densidade de indivíduos por hectare foi estimada foi 2.306 ind.ha $^{-1}$. Machaerium paraguariense Hassl. apresentou os maiores valores de densidade (367 ind.ha ${ }^{-1}$ ) e também de IVI $(16,0)$. A diversidade florística estimada pelos índices de H' e J resultou em 3,09 nats.ind. $^{-1}$ e 0,84 , respectivamente. Apesar de ser constituído por uma estreita faixa de mata, o fragmento estudado encontra-se em bom estado de conservação, pois apresenta altos índices de diversidade e o registro de apenas duas espécies exóticas, ambas com baixo IVI.
\end{abstract}

Palavras chaves: Bacia Hidrográfica do Rio Taquari-Antas. Floresta de galeria. Florística. Formação ribeirinha. Fitossociologia. Mata ribeirinha.

\begin{abstract}
The riparian forests are fundamental for the protection of water springs. This study intended to investigate the community arboreal structure of a Taquari River riparian fragment, in Colinas, Rio Grande do Sul. The sample was done through the distribution of 18 sampling units of $100 \mathrm{~m}^{2}$, taken every 20 meters, forming a transect parallel to the river. In the units were sampled the individuals which had from the circumference of the stem to the height of the chest equal or higher than $20 \mathrm{~cm}$. The parameters of density, frequency and dominance, absolute and relatives, and the index of importance value (IVI) were defined and the diversity was estimated for the Shannon (H') and equability of Pielou (J). 415 individuals, 39 species and 21 botanical families were sampled, being Fabaceae the family with higher wealth. The individuals density for hectare were estimated in 2.306 ind.ha $^{-1}$. Machaerium paraguariense Hassl showed the highest values of density $\left(367\right.$ ind.ha $\left.^{-1}\right)$ and also of IVI $(16,0)$. The floristic

\footnotetext{
${ }^{1}$ Graduanda de Ciências Biológicas, Centro Universitário UNIVATES. <mareliset01@gmail.com>

${ }^{2}$ Graduanda de Ciências Biológicas, Centro Universitário UNIVATES. < $\underline{\text { alinemarjana@gmail.com> }}$

${ }^{3}$ Graduando de Ciências Biológicas, Centro Universitário UNIVATES.<1ucasc09_7@ hotmail.com>

${ }^{4}$ Biólogo pelo Curso de Ciências Biológicas, Centro Universitário UNIVATES.<gaga@ universo.univates.br>

${ }^{5}$ Doutora em Botânica, Programa de Pós-Graduação em Biotecnologia e Programa de Pós-Graduação em Ensino.

Centro Universitário UNIVATES. <elicauf@ univates.br>
} 
diversity estimated for the indexes of $\mathrm{H}^{\prime}$ and $\mathrm{J}$ resulted in 3,09 nats.ind. $^{-1}$ and 0,84 , respectively. Despite being constituted in a narrow fragment of forest, the fragment studied finds itself in a good state of conservation, because it shows high diversity indexes and the registration of just two exotic species, both with low IVI.

Keywords: Taquari-Antas River Hydrological Basin. Gallery forest. Floristic. Riverside formation. Phytosociology. Riverside forest.

\section{INTRODUÇÃO}

As matas ciliares margeiam corpos d'água, como riachos, rios e lagoas, apresentando comumente porte arbóreo ou arbustivo em ambientes não perturbados (JACOMASSA, 2010). Elas são caracterizadas por apresentarem acentuada heterogeneidade florística e pela dinâmica sucessional de suas formações. Esta heterogeneidade pode ser ocasionada por perturbações naturais relacionadas aos processos de dinâmica da água e sua distribuição no solo, pelo tamanho da faixa ciliar florestada, estado de conservação ou degradação desses remanescentes, pela matriz vegetacional onde a formação vegetal está inserida e interação dos fatores físicos e biológicos do ambiente ciliar (RODRIGUES; SHEPHERD, 2001). Arizpe et al. (2008), por exemplo, afirmam que a vegetação difere conforme o relevo. Nas depressões apresenta espécies vegetais que toleram longos períodos de alagamento enquanto que em locais mais altos, as espécies são típicas de ambientes bem drenados.

As formações ciliares constituem corredores importantes para o movimento da fauna ao longo da paisagem, assim como para a dispersão vegetal (LIMA; ZAKIA, 2001), constituindo um habitat valioso para a fauna e a flora nativas e proteção contra a erosão (SEPA, 2009). São os benefícios que este tipo de vegetação traz aos ecossistemas, ao exercer função protetora sobre os recursos naturais bióticos e abióticos, que ressaltam a necessidade da sua preservação ou restauração quando degradadas (JACOMASSA, 2010).

Apesar da importância que apresentam e de estarem protegidas pela legislação brasileira desde 1965 através do Código Florestal (Lei nº 4.771) (BRASIL, 1965), as matas ciliares não foram poupadas da devastação ao longo do tempo como consequência da inadequação das políticas públicas brasileiras, da indiferença do poder público em relação às questões ambientais e da fiscalização quase inexistente (RODRIGUES; NAVE, 2001).

As matas ciliares dos rios e arroios que formam Bacia Hidrográfica do Rio TaquariAntas (BHRTA) são testemunhas da falta de controle e de exigências quanto ao cumprimento da legislação vigente no país, pois se encontram intensamente degradadas. Segundo Lima et al. (2007), somente $26 \%$ das matas ciliares desta bacia apresentam vegetação de floresta. 
Apesar disso, são poucos os estudos nas áreas remanescentes desta Bacia, assim como em todo o Rio Grande do Sul (RS) (AVILA et al., 2011). Na BHRTA, são apenas dois trabalhos realizados. Mundeleski et al. (2008) dimensionou a ocupação de Hovenia dulcis Thumb, espécie exótica de comportamento invasor, no Arroio Jacarezinho em Nova Bréscia e Encantado. Brackmann e Freitas (2013) apresentaram a lista florística de espécies arbóreas e arbustivas existentes em um fragmento de mata ciliar do arroio Bela Vista no município de Teutônia.

Diante da falta de informações quanto à estrutura das comunidades vegetais das matas ciliares e da necessidade de embasar a implantação de projeto de recuperação destes remanescentes quando degradados, o estudo teve como objetivo, conhecer a composição florística e fitossociológica do estrato arbóreo de uma estreita faixa de mata ciliar do Rio Taquari, no município de Colinas, Rio Grande do Sul (RS), Brasil.

\section{MATERIAL E MÉTODOS}

\section{1 Área de estudo}

$\mathrm{O}$ estudo foi realizado em uma faixa de mata ciliar na margem esquerda do Rio Taquari, no Município de Colinas, Rio Grande do Sul (RS), Brasil, situada entre as

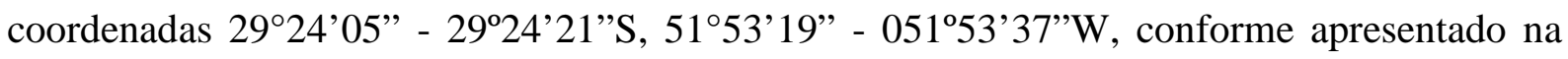
Figura 1. A área constitui um pequeno fragmento com largura entre 10 e 20 metros e extensão de aproximadamente $520 \mathrm{~m}$ e que faz limites com áreas agrícolas.

Figura 1 - Localização da área de estudo no Rio Grande do Sul e no município de Colinas. No detalhe, extensão da área na margem do Rio Taquari.

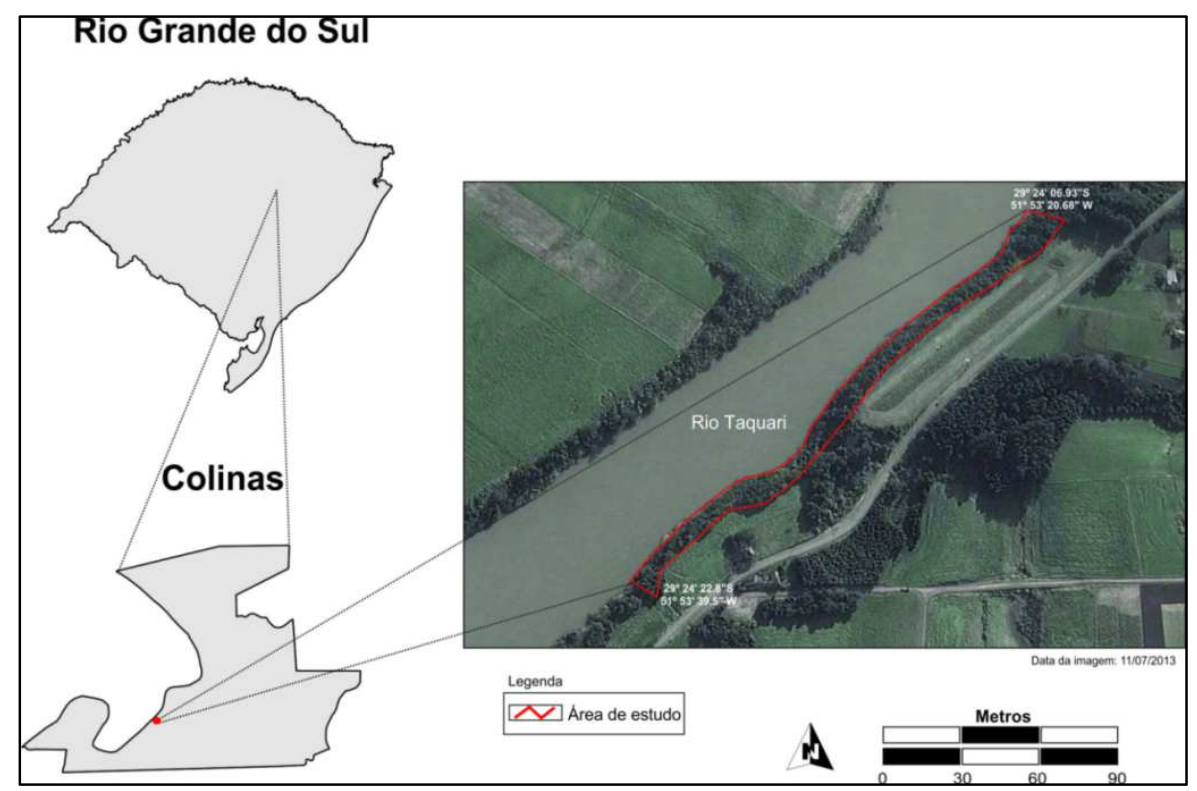


O Rio Taquari faz parte da Bacia Hidrográfica do Rio Taquari-Antas que apresenta, especialmente na porção onde o fragmento está localizado, áreas de alto índice de industrialização, com predomínio de produção primária, intensa urbanização e riscos de ocorrência de enchentes (FEPAM, 2013). Grande parte da extensão de mata estudada, que possui no máximo 15 metros de largura, faz limites com lavouras, sendo a implantação de áreas agricultáveis uma das causas da redução em largura e da fragmentação.

O clima da região é do tipo clima temperado húmido com verão quente (cfa) (PELL et al., 2007). O solo, com razoáveis teores de material orgânico e alta fertilidade química, típico das várzeas dos rios que drenam a Encosta Inferior do Nordeste, é classificado como Chernossolo Háplico Órtico (STRECK et al., 2008). A vegetação do município está inserida na formação fitoecológica da Floresta Estacional Decidual, Bioma Mata Atlântica (IBGE, 2004).

\subsection{Levantamento fitossociológico}

A amostragem do componente arbóreo foi realizada através do método de área fixa com a distribuição de 18 parcelas (UA's) de $100 \mathrm{~m}^{2}$ a cada 20 metros ao longo da margem do rio, formando um único transecto paralelo ao rio. Em cada UA foram amostrados todos os indivíduos com CAP (circunferência à altura do peito $=1,30 \mathrm{~m}$ de altura do solo) $\geq 20 \mathrm{~cm}$, sendo incluídos também todos os indivíduos sobre a linha dos limites das UA's. No caso dos espécimes com mais de um fuste, foi considerada cada uma das medidas, anotadas separadamente, para efetuar o cálculo de área basal do indivíduo. Árvores mortas ainda em pé, presentes nas parcelas e com critério mínimo de inclusão, foram amostradas e colocadas em uma classe única, não participando dos cálculos fitossociológicos. Além da medida do CAP, a altura total das árvores foi estimada visualmente.

De cada uma das espécies encontradas nas UA's, identificadas ou não in loco, foi realizada a coleta de material botânico fértil ou não. $\mathrm{O}$ material coletado foi desidratado e identificado com o uso de chaves dicotômicas específicas (SOBRAL et al., 2006) e com consulta à especialistas. Quando fértil, o material foi herborizado e incorporado ao acervo do Herbário HVAT (Herbário do Vale do Taquari) do Museu de Ciências Naturais do Centro Universitário UNIVATES. Para a elaboração a lista de espécies encontradas durante o levantamento, as famílias foram classificadas de acordo com Angiosperm Phylogeny Group III (APG III, 2009) e os nomes científicos das espécies nativas foram confirmados na Lista de Espécies da Flora do Brasil (2014). As espécies exóticas seguiram a nomenclatura do Missouri Botanical Garden (TROPICOS ORG., 2014). 


\subsection{Análise dos dados}

Para cada uma das espécies amostradas, foram definidos os parâmetros de área basal $(A B)$, densidade (D), frequência (F) e dominância (Do), absolutas (A) e relativas $(\mathrm{R})$, e o índice de valor de importância (IVI) (MÜLLER-DOMBOIS; ELLEMBERG, 1974). A riqueza de espécies na área amostrada foi estimada pelo Sobs (Mao Tau) no programa EstimateS versão 9.1.0 (COLWELL, 2013). A diversidade do componente arbóreo foi estimada através do índice de Shannon (H') e a equabilidade pelo índice de Pielou (J'), utilizando o programa Past versão 3.0 (HAMMER, 2001).

\section{RESULTADOS E DISCUSSÃO}

\subsection{Estrutura da comunidade}

Foram amostrados 426 indivíduos, dos quais 415 eram vivos. Os indivíduos vivos distribuíram-se em 39 espécies, 36 gêneros e 21 famílias botânicas. O estimador de riqueza Sobs estimou um limite máximo de 44 espécies para a área, valores próximos aos encontrados (39), indicando que a amostra correspondeu a $88,6 \%$ da riqueza total estimada, conforme Figura 2.

Figura 2 - Estimativa de riqueza de espécies pelo estimador "Sobs" para a área amostrada. As barras correspondem ao desvio padrão.

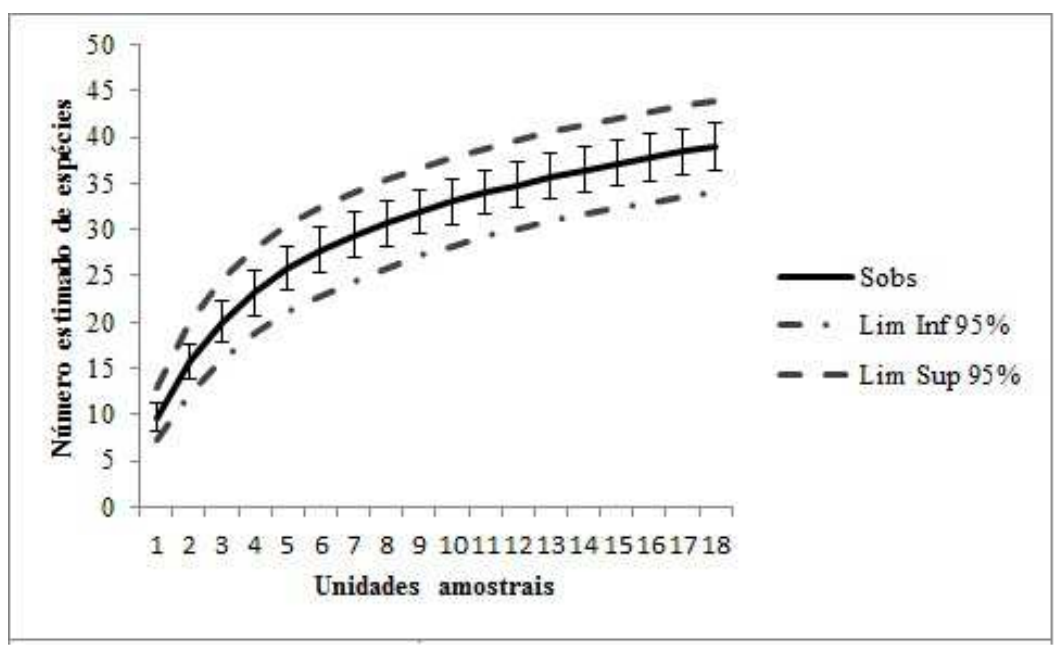

Do total de espécies registradas, duas são exóticas (Morus nigra e Melia azedarach), no entanto, ambas apresentaram baixos valores de IVI (0,3 e 0,28, respectivamente). Dentre as demais, três se encontram na Lista da Flora Ameaçada do RS na categoria vulnerável: Apuleia leiocarpa, Myrocarpus frondosus e Picrasma crenata (RIO GRANDE DO SUL, 2003). Foram amostrados 18 indivíduos de M. frondosus, dois de A. leiocarpa e apenas um de P. crenata. 
A família com maior riqueza foi Fabaceae, com oito espécies $(20,5 \%)$, seguida por Myrtaceae e Sapindaceae, com três espécies (7,7\% cada). A família Meliaceae também apresentou 7,7\% de espécies, no entanto, uma foi exótica. As famílias Euphorbiaceae, Lauraceae, Moraceae, Polygonaceae e Sapotaceae foram representadas por duas espécies (5,1\% cada). As 12 famílias restantes $(30,8 \%)$ foram representadas por apenas uma espécie.

Figura 3 - Percentual de espécies por famílias botânicas registradas na mata ciliar do Rio Taquari, Colinas, RS, Brasil.

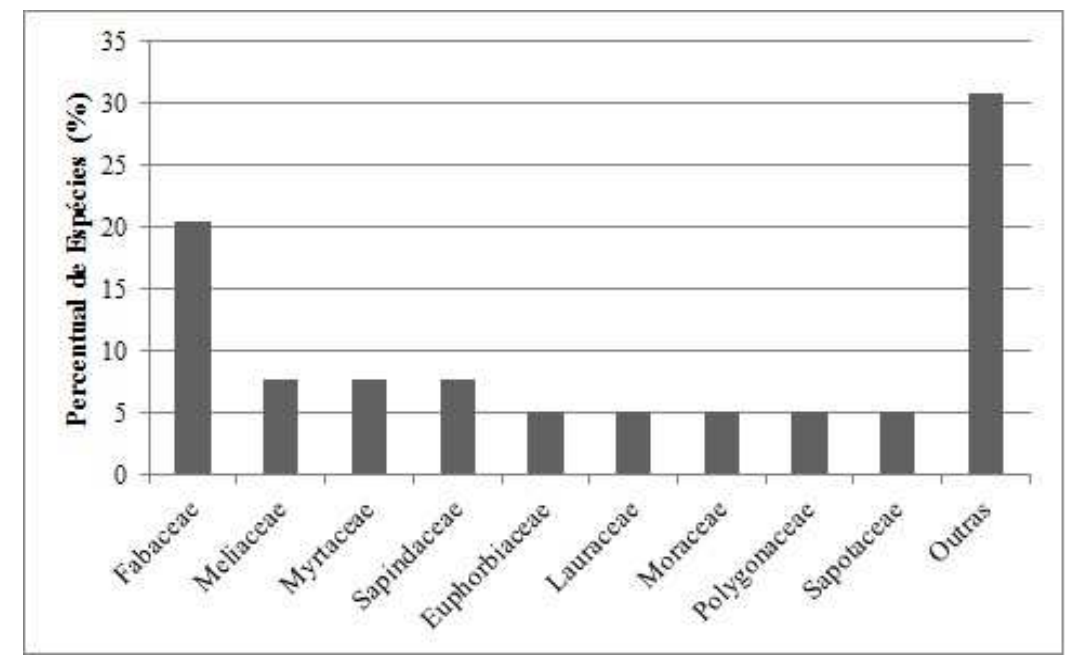

Outras: corresponde a 12 famílias representadas por uma única espécie.

Jacomassa (2011), ao estudar a florística de um fragmento de mata ciliar da Bacia Hidrográfica do Rio Lajeado Tuna, em Frederico Westphalen no RS, também registrou a família Fabaceae como a mais representativa, seguida por Myrtaceae. A família Fabaceae também foi apontada por Avila et al. (2011) e Giehl e Jarenkow (2008) como a mais numerosa em matas ciliares do RS, seguida por Myrtaceae. Na mesma Bacia do presente estudo, Brackmann e Freitas (2013) registraram o maior número de espécies para a família Fabaceae (11), seguida por Euphorbiaceae e Myrtaceae na segunda posição, ambas com quatro espécies. Já Mundeleski et al. (2008), também na mesma Bacia, registraram o inverso, ficando Myrtaceae na primeira posição, seguida por Fabaceae.

A densidade de indivíduos por hectare foi estimada em 2.305,56 ind.ha ${ }^{-1}$, um número alto e superior ao de outros levantamentos, embora de tamanho bem inferior. Budke et al. (2004) registraram densidade de 2.195 ind./ha ${ }^{-1}$ numa floresta ribeirinha contínua, com 20 ha, no arroio Passo das Tropas, Santa Maria - RS, considerando indivíduos com CAP $\geq$ 15. Outro exemplo é o trabalho de Marchi e Jarenkow (2008), em que estimaram uma densidade total de 2.179 ind.ha $^{-1}$ ao realizar o levantamento de um fragmento de mata ciliar do Rio Camaquã em Cristal, RS. As espécies com os maiores valores de densidade absoluta foram Machaerium paraguariense (367 ind.ha ${ }^{-1}$ ), Annona neosalicifolia (183 ind.ha ${ }^{-1}$ ), 
Eugenia uniflora (167 ind.ha $\left.{ }^{-1}\right)$ e Nectandra megapotamica $\left(161\right.$ ind.ha $\left.^{-1}\right)$. As quatro espécies somam 38,34\% da densidade absoluta total, como pode ser visualizado na Tabela 1.

Tabela 1 - Parâmetros fitossociológicos das espécies florestais de um fragmento de mata ciliar no rio Taquari, em Colinas (RS)

\begin{tabular}{|c|c|c|c|c|c|c|}
\hline Espécie & Familia & $\mathbf{N i}$ & DA & DoA & FA & IVI \\
\hline Machaerium paraguariense Hassl. & Fabaceae & 66 & 366,67 & 14,07 & 88,89 & 15,98 \\
\hline Nectandra megapotamica (Spreng.) Mez & Lauraceae & 29 & 161,11 & 5,48 & 38,89 & 6,63 \\
\hline Myrocarpus frondosus Allemão\# & Fabaceae & 18 & 100,00 & 5,94 & 38,89 & 6,00 \\
\hline Annona neosalicifolia H.Rainer & Annonaceae & 33 & 183,33 & 2,59 & 50,00 & 5,74 \\
\hline Trichilia clausseni C.DC. & Meliaceae & 25 & 138,89 & 2,11 & 72,22 & 5,57 \\
\hline Eugenia uniflora L. & Myrtaceae & 30 & 166,67 & 2,86 & 44,44 & 5,46 \\
\hline Luehea divaricata Mart. \& Zucc. & Malvaceae & 20 & 111,11 & 3,86 & 44,44 & 5,20 \\
\hline $\begin{array}{l}\text { Sebastiania commersoniana (Baill.) } \\
\text { L.B.Sm. \& Downs }\end{array}$ & Euphorbiaceae & 24 & 133,33 & 1,78 & 55,56 & 4,76 \\
\hline Parapiptadenia rigida (Benth.) Brenan & Fabaceae & 21 & 116,67 & 0,89 & 55,56 & 4,02 \\
\hline $\begin{array}{l}\text { Chrysophyllum gonocarpum (Mart. \& } \\
\text { Eichler ex Miq.) Engl. }\end{array}$ & Sapotaceae & 13 & 72,22 & 1,28 & 50,00 & 3,41 \\
\hline Casearia sylvestris $\mathrm{Sw}$ & Salicaceae & 19 & 105,56 & 1,03 & 38,89 & 3,39 \\
\hline $\begin{array}{l}\text { Cordia Americana (L.) Gottschling \& } \\
\text { J.S.Mill. }\end{array}$ & Boraginaceae & 8 & 44,44 & 2,81 & 27,78 & 3,11 \\
\hline Lonchocarpus nitidus (Vogel) Benth. & Fabaceae & 9 & 50,00 & 1,20 & 44,44 & 2,86 \\
\hline Bauhinia forficata Link & Fabaceae & 15 & 83,33 & 0,66 & 33,33 & 2,68 \\
\hline $\begin{array}{l}\text { Allophylus edulis (A.St.-Hil.et al.) Hierin. } \\
\text { Ex Niederl. }\end{array}$ & Sapindaceae & 10 & 55,56 & 0,83 & 38,89 & 2,56 \\
\hline Apuleia leiocarpa (Vogel) J.F.Macbr.\# & Fabaceae & 2 & 11,11 & 3,66 & 11,11 & 2,53 \\
\hline Diospyros inconstans Jacq. & Ebenaceae & 6 & 33,33 & 2,34 & 16,67 & 2,32 \\
\hline Zanthoxylum caribaeum Lam. & Rutaceae & 5 & 27,78 & 1,32 & 27,78 & 2,05 \\
\hline Machaerium stipitatum Vogel & Fabaceae & 6 & 33,33 & 0,94 & 27,78 & 1,92 \\
\hline $\begin{array}{l}\text { Chrysophyllum marginatum (Hook. \& Arn.) } \\
\text { Radlk. }\end{array}$ & Sapotaceae & 10 & 55,56 & 0,81 & 16,67 & 1,80 \\
\hline Aiouea saligna Meisn. & Lauraceae & 4 & 22,22 & 1,12 & 11,11 & 1,31 \\
\hline Trichilia elegans A.Juss. & Meliaceae & 6 & 33,33 & 0,26 & 16,67 & 1,18 \\
\hline Aspidosperma riedelii Müll.Arg. & Apocynaceae & 4 & 22,22 & 0,77 & 11,11 & 1,11 \\
\hline Actinostemon concolor (Spreng.) Müll.Arg. & Euphorbiaceae & 6 & 33,33 & 0,24 & 11,11 & 0,98 \\
\hline Myrciaria cuspidata O.Berg & Myrtaceae & 3 & 16,67 & 0,19 & 16,67 & 0,90 \\
\hline Strychnos brasiliensis Mart. & Loganiaceae & 3 & 16,67 & 0,15 & 16,67 & 0,88 \\
\hline Matayba elaeagnoides Radlk. & Sapindaceae & 3 & 16,67 & 0,11 & 16,67 & 0,86 \\
\hline Ruprechtia laxiflora Meisn. & Polygonaceae & 4 & 22,22 & 0,21 & 11,11 & 0,81 \\
\hline $\begin{array}{l}\text { Campomanesia xanthocarpa (Mart.) } \\
\text { O.Berg }\end{array}$ & Myrtaceae & 3 & 16,67 & 0,28 & 11,11 & 0,77 \\
\hline Maclura tinctoria (L.) D.Don ex Steud. & Moraceae & 1 & 5,56 & 0,34 & 5,56 & 0,45 \\
\hline Picrasma crenata (Vell.) Engl.\# & Simaroubaceae & 1 & 5,56 & 0,27 & 5,56 & 0,41 \\
\hline Seguieria aculeata Jacq. & Phytolaccaceae & 1 & 5,56 & 0,08 & 5,56 & 0,31 \\
\hline Morus nigra L.* & Moraceae & 1 & 5,56 & 0,07 & 5,56 & 0,30 \\
\hline Coccoloba cordata Cham. & Polygonaceae & 1 & 5,56 & 0,07 & 5,56 & 0,30 \\
\hline Mimosa bimucranata (DC.) Kuntze & Fabaceae & 1 & 5,56 & 0,06 & 5,56 & 0,30 \\
\hline
\end{tabular}


Erythroxylum argentinum O.E.Schulz

Melia azedarach. L.*

Cupania vernalis Cambess.

Celtis iguanaea (Jacq.) Sarg.

$\begin{array}{llllll}\text { Erythroxylaceae } & 1 & 5,56 & 0,04 & 5,56 & 0,29 \\ \text { Meliaceae } & 1 & 5,56 & 0,03 & 5,56 & 0,28 \\ \text { Sapindaceae } & 1 & 5,56 & 0,02 & 5,56 & 0,28 \\ \text { Cannabaceae } & 1 & 5,56 & 0,02 & 5,56 & 0,28\end{array}$

[Ni - número de indivíduos; DA - densidade absoluta (ind.ha $\left.{ }^{-1}\right)$; DoA - dominância absoluta $\left(\mathrm{m}^{2} \cdot \mathrm{ha}^{-1}\right) ; \mathrm{FA}$ frequência absoluta (\%) e Índice de Valor de importância (IVI); \# - espécies ameaçadas; * - espécies exóticas].

Em relação à área basal, os maiores valores encontrados foram de $M$. paraguariense (2,53), Myrocarpus frondosus (1,07), Nectandra megapotamica $(0,99)$ e Luehea divaricata (0,70). A espécie Luehea divaricata não esteve entre as espécies com os maiores valores de DA, DoA, FA (Frequência absoluta) e IVI, no entanto, teve a quarta maior área basal devido ao elevado diâmetro dos seus indivíduos. As espécies que apresentaram os maiores valores de FA foram $M$. paraguariense (88,89\%), seguida por Trichilia clausseni (72,22\%), Parapiptadenia rigida e Sebastiania commersoniana, ambas com 55,56\% e Annona neosalicifolia e Chrysophyllum gonocarpum, com 50\%. As espécies T. clausseni, P. rigida e S. commersoniana tiveram alta frequência na área amostrada, aparecendo em mais de $50 \%$ das UA's. Apesar disto, não estão entre as espécies de maior IVI, pois são árvores de pequeno porte e não apresentaram área basal acentuada.

M. paraguariense, além da maior FA e área basal, atingiu os maiores valores em todos os parâmetros avaliados e, consequentemente, ficou na primeira posição dentre todas as espécies em relação ao IVI $(15,98)$. A sua presença marcante deve-se à sua adaptação em florestas aluviais (SILVA et al., 2012). Confirmando tal afirmação, a espécie também foi registrada em outros levantamentos em matas ciliares no RS (BUDKE et al., 2004; OLIVEIRA et al., 2005; AVILA et al., 2011; BRACKMANN; FREITAS, 2013). A espécie foi seguida, com valores bem inferiores, por Nectandra megapotamica (6,63), Myrocarpus frondosus $(6,00)$ e Annona neosalicifolia $(5,74)$. N. megapotamica, com o segundo maior IVI no presente estudo, esteve entre as espécies de maior IVI no estudo de Marchi e Jarenkov (2008) e de maior IVI na área alagável no Parque Estadual Mata dos Godoy em Londrina, Paraná, em estudo realizado por Bianchini et al. (2003).

Dentre as espécies amostradas no levantamento, dez foram representadas por apenas um indivíduo, podendo ser consideradas raras, segundo Martins (1991), pois este autor afirma que espécies com baixos valores de densidade e frequência são assim consideradas. No caso das matas ciliares, estes resultados podem ser um alerta para a ameaça que estas importantes formações florestais vêm sofrendo como consequência da acentuada degradação.

Com riqueza (S) de 39 espécies e índices de diversidade de Shannon (H') e equabilidade (J') de Pielou de 3,09 nats.ind. ${ }^{-1}$ e 0,84, respectivamente, pode-se afirmar que 
estes são valores elevados quando comparados com outros trabalhos realizados em matas ciliares do RS. É o caso, por exemplo, de Budke et al. (2004), que encontraram $\mathrm{S}=57, \mathrm{H}=$ 2,73 nats.ind. $^{-1}$ e equabilidade de Pielou de 0,69, ou do trabalho de Marchi e Jarenkov (2008) no Rio Camaquã, cujos valores de Shannon e equabilidade de Pielou foram, respectivamente, 2,342 e 0,695. Ávila et al. (2011) registraram no Rio Ijuí $\mathrm{S}=38$ e H'=3,02 nats.ind. ${ }^{-1}$, enquanto que Soares e Ferrer (2009), no Rio Piratini, no sudeste do RS, obtiveram $S=40$ e $H^{\prime}=2,99$ nats.ind. ${ }^{-1}$. Já Dorneles et al. (2013), no Arroio Bolaxa em Rio Grande (RS), encontraram $\mathrm{S}=26$ e H' $=2,58$ nats.ind. ${ }^{-1}$. Deve-se considerar, ainda, que a área estudada é formada por uma estreita faixa de mata, com aproximadamente 520 metros de extensão, que faz limite com uma área de lavoura. Giehl e Jarenkow (2008) registraram valores mais altos no trabalho realizado em um hectare de floresta no Rio Uruguai, sendo eles $\mathrm{S}=82$ e $\mathrm{H}^{\prime}=$ 3,68 nats.ind. ${ }^{-1}$.

A altura estimada da vegetação variou de 2 a 26 metros, com altura média de $9 \mathrm{~m}$. A distribuição dos indivíduos por classes de altura indicou que 65\% (277) dos indivíduos amostrados apresentaram entre 4,0 e 9,0 de altura. Esses resultados mostram e existência de poucas árvores emergentes.

Figura 4 - Distribuição do número de indivíduos amostrados no fragmento de mata ciliar do Rio Taquari, Colinas, RS, por classe de altura de 1 metro.

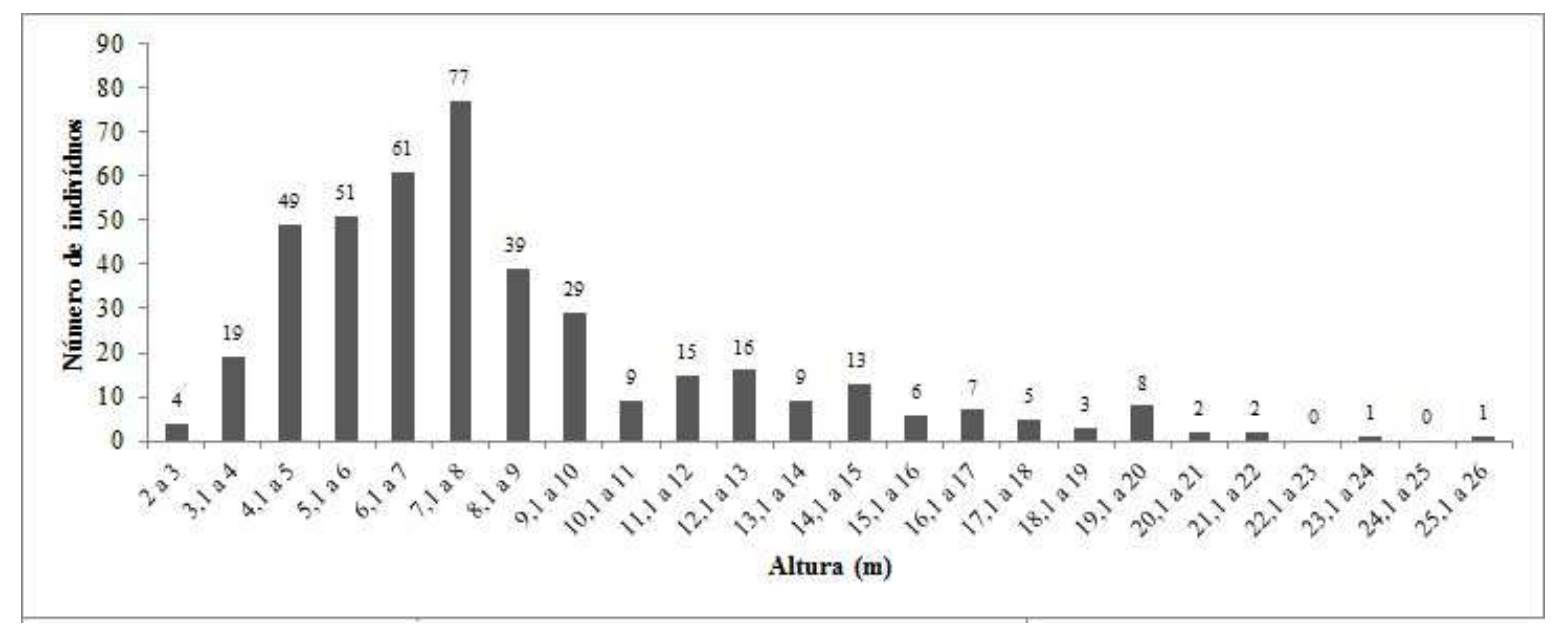

As classes de diâmetros variaram de 5,0 cm a 130,0 cm (Figura 5), sendo 6,4 cm o menor e 127,7 cm, o maior diâmetro registrado. As cinco primeiras classes (5,0 a 30,0 cm) concentraram a maioria dos indivíduos $(86,4 \%)$, enquanto que o percentual de indivíduos com diâmetros maiores de $50,0 \mathrm{~cm}$ foi de apenas $6,8 \%$. Houve redução evidente no número de indivíduos na medida em que aumentou a classe de diâmetro. Na menor classe $(5,0$ a 10,0 cm) 
houve maior concentração de indivíduos $(31,9 \%)$, correspondendo às espécies típicas do subbosque e de regenerantes das espécies do dossel.

Figura 5 - Distribuição do número de indivíduos por classes de diâmetro, com amplitude de $5,0 \mathrm{~cm}$, no fragmento de mata ciliar do Rio Taquari, Colinas, RS.

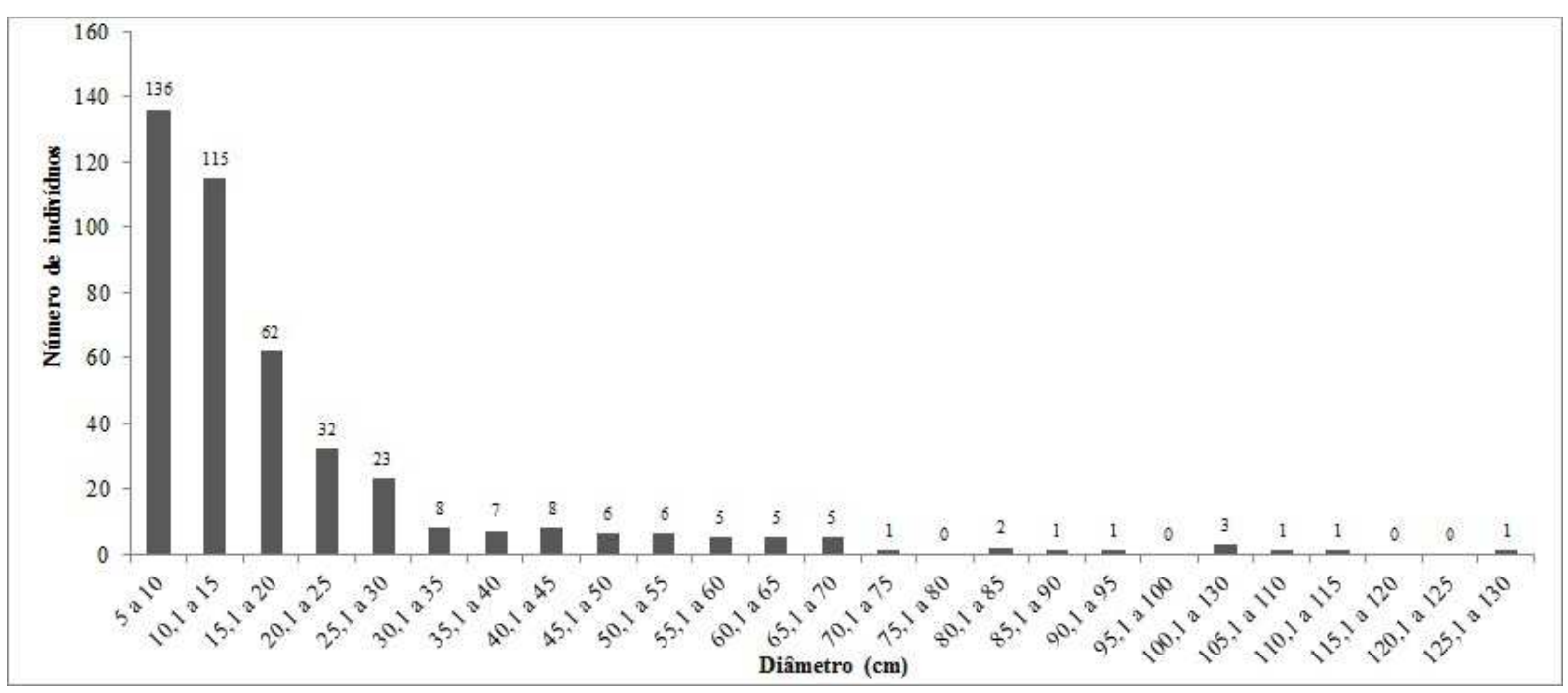

\section{CONCLUSÃO}

Apesar de a área ser constituída por uma estreita faixa de mata ciliar remanescente e de extensão reduzida, os índices de diversidade registrados são altos em relação a outras áreas de mata ciliar estudadas. O registro de poucas espécies exóticas reforça o grau de diversidade da área. Por outro lado, várias espécies foram representadas por um reduzido número de indivíduos, o que pode comprometer no futuro esta diversidade se nenhuma ação for adotada para a sua preservação e ampliação dos seus atuais limites, tanto de extensão como de largura.

\section{AGRADECIMENTOS:}

À Fundação de Amparo à Pesquisa do Estado do Rio Grande do Sul (FAPERGS) pelo financiamento da pesquisa e bolsas concedidas. Ao Centro Universitário UNIVATES pela estrutura de laboratório e material disponibilizado para a realização da pesquisa. Aos bolsistas Gerson Luiz Ely Junior, Letícia Rodrigues Vieira e Norton Dametto pelo auxílio nas atividades. À Martin Grings pelo auxílio na identificação e confirmação das espécies. À Úrsula Arend pela confecção do mapa. 


\section{REFERÊNCIAS}

APG III - Angiosperm Phylogeny Group. Anupdate of the Angiosperm Phylogeny pdate of the Angiosperm Phylogeny Group classification for the orders and families of flowering plants. Botanical Journal of the Linnean Society, n. 161, p. 105-121, 2009.

ARIZPE, D.; MENDES, A.; RABAÇA, J. E. (Eds.). Sustainable Riparian Zones: A Management Guide. Generalitat Valenciana, 2008. Disponível em: $<$ https://dspace.uevora.pt/rdpc/bitstream/10174/6864/1/Sustainable\%20Riparia\%20Zonesa\%20management\%20guide.pdf>. Acesso em: 18 de fev. de 2014.

AVILA, A. L.; ARAUJO, M. M.; LONGHI, S. J.; GASPARIN, E. Caracterização da vegetação e espécies para recuperação de mata ciliar, Ijuí, RS. Ciência Florestal, v. 21, n. 2, p. 251-260, 2011.

BIANCHINI, E.; POPOLO, R. S.; DIAS, M. C.; PIMENTA, J. A. Diversidade e estrutura de espécies arbóreas em uma área alagável do município de Londrina, sul do Brasil. Acta Botanica Brasilica, Feira de Santana, v. 17, n. 3, p. 405-419, 2003.

BRACKMANN, C. E.; FREITAS, E. M. Florística arbórea e arbustiva de um fragmente de Mata Ciliar do arroio Boa Vista, Teutônia, RS, Brasil. Hoehnea, São Paulo, v. 40, n. 2, p. 365-372, 2013.

BRASIL. Lei $n^{o} 4.771$, de 15 de setembro de 1965. Institui o novo Código Florestal. Disponível em: <http://www.planalto.gov.br/ccivil_03/leis/L4771.htm>. Acesso em: 02 de jul. de 2013.

BUDKE, J. C.; GIEHL, E. L. H.; ATHAYDE, E. A.; EISINGER, S. M.; ZÁCHIA, R. A. Florística e fitossociologia do componente arbóreo de uma floresta ribeirinha, arroio Passo das Tropas, Santa Maria, RS, Brasil. Acta Botânica Brasílica, Feira de Santana, v. 18, n. 3, p. 581-589, 2004.

COLWELL, R. K. EstimateS: Statistical Estimation of Species Richness and Shared Species from Samples. Version 9.1.0. Connecticut: University of Connecticut. 2006. Disponível em: <http://purl.oclc.org/estimates〉. Acesso em: 28 de fev. de 2014.

DORNELES, L. P. P.; GUTIERRES, V. S.; BIANCHIN, A.; TELÖKEN, F. Estrutura do componente arbóreo de uma floresta ribeirinha da Planície Costeira do Rio Grande do Sul, Brasil. Iheringia, sér. Bot., Porto Alegre, v. 68, n. 1, p. 37-46, 2013.

FEPAM - Fundação Estadual de Proteção Ambiental Henrique Luiz Roessler. Qualidade das Águas da Bacia Hidrográfica do Rio das Antas e Rio Taquari. Disponível em: $\langle$ http://www.fepam.rs.gov.br/qualidade/qualidade_taquari_antas/taquariantas.asp $>$. Acesso em: 24 de out. de 2013.

GIEHL, E. L. H.; JARENKOW, J. A. Gradiente estrutural no componente arbóreo e relação com inundações em uma floresta ribeirinha, rio Uruguai, sul do Brasil. Acta Botanica Brasilica. Feira de Santana, v. 22, n. 3, p. 741-753. 
HAMMER, Ø.; HARPER, D. A. T.; RYAN, P. D. PAST: Paleontological Statistics Software Package for Education and Data Analysis. Palaeontologia Electronica, Ottawa, v. 4, n. 1, p. $1-9,2001$.

IBGE - Instituto Brasileiro de Geografia e Estatística. IBGE lança o Mapa de Biomas do Brasil e o Mapa de Vegetação do Brasil, em comemoração ao Dia Mundial da Biodiversidade. Comunicação Social, 21 de maio de 2004. Disponível em: <http://www.ibge.gov.br/home/presidencia/noticias/noticia_visualiza.php?id_noticia=169>.

Acesso em: 21 de ago. de 2013.

JACOMASSA, F. A. F. Espécies arbóreas nativas da mata ciliar da Bacia Hidrográfica do Rio Lajeado Tunas, na região do Alto Uruguai, RS. Biodiversidade Pampeana, Uruguaiana, v. 8, n. 1, p. 1-6, 2010.

LIMA, D. F. B.; REMPEL, C.; ECKHARDT, R. R. Análise Ambiental da Bacia Hidrográfica do Rio Taquari Proposta de Zoneamento Ambiental. Geografia, Londrina, v. 16, n. 1, p. 5178, 2007.

LIMA, W. P.; ZAKIA, M. J. B. Hidrologia de matas ciliares. In: In: RODRIGUES, R. R.; LEITÃO FILHO, H. F. (eds). Matas Ciliares: conservação e recuperação. São Paulo: Editora da Universidade de São Paulo/Fundação de Amparo à Pesquisa do Estado de São Paulo, 2001.

LISTA DE ESPÉCIES DA FLORA DO BRASIL. Jardim Botânico do Rio de Janeiro. Disponível em: 〈http://floradobrasil.jbrj.gov.br>. Acesso em: 04 de mar. de 2014

MARCHI, T. C.; JARENKOW, J. A. Estrutura do componente arbóreo de mata ribeirinha no rio Camaquã, município de Cristal, Rio Grande do Sul, Brasil. Iheringia, Sér. Bot., Porto Alegre, v. 63, n. 2, p. 241-248, 2008.

MARTINS, F.R. Estrutura de uma floresta mesófila. Campinas: Editora da UNICAMP, 1991

MUELLER-DOMBOIS, D.; ELLENBERG, H. Aims and methods of vegetation ecology. New York: John Wiley, 1974.

MUNDELESKI, E.; SCHMITZ, J. A. K.; BIONDO, E. Estudo Ambiental da microbacia do arroio jacarezinho (Nova Bréscia e Encantado, RS) com ênfase na mata ciliar e na qualidade da água. Caderno de Pesquisa, Série Biologia, Santa Cruz do Sul, v. 20, n. 3, p. 44-61, 2008.

OLIVEIRA, M. De L. A. A.; BALBUENO, R. A.; SENNA, R. M. Levantamento florístico de fragmentos florestais na bacia hidrográfica do rio Gravataí, Rio Grande do Sul, Brasil. Iheringia, Sér. Bot., Porto Alegre, v. 60, n. 2, p. 269-284, 2005.

PEEL, M. C.; FINLAYSON, B. L.; MCMAHON, T. A. Updated world map of the KöppenGeiger climate classification. Hydrology and Earth System Sciences. European Geosciences Union, v. 11, p. 1633-1644, 2007.

RODRIGUES, R. R.; SHEPHERD, G. J. Fatores condicionantes da vegetação ciliar. In: RODRIGUES, R. R.; LEITÃO FILHO, H. F. Matas Ciliares: conservação e recuperação. São Paulo: Editora da Universidade de São Paulo/Fundação de Amparo à Pesquisa do Estado de São Paulo, 2001. 
RODRIGUES, R. R.; NAVE, A. G. Heterogeneidade Florística das Matas Ciliares. In: RODRIGUES, R. R.; LEITÃO FILHO, H. F. Matas Ciliares: conservação e recuperação. São Paulo: Editora da Universidade de São Paulo/Fundação de Amparo à Pesquisa do Estado de São Paulo, 2001.

RIO GRANDE DO SUL - Decreto Estadual no 42.099, publicado em 01/01/2003. Lista Final das espécies da Flora Ameaçadas - RS. 2003. Disponível em: <http://www.fzb.rs.gov.br/downloads/flora_ameacada.pdf>. Acesso em: 02 de set. de 2013.

SEPA - Scottish Environment Protection Agency. Engineering in the Water Environment Good Practice Guide: Riparian Vegetation Management. 2009. Disponível em: <http://www.sepa.org.uk/water/water_publications.aspx >. Acesso em: 05 de mar. de 2014.

SILVA, A. C. da; HIGUCHI, P.; VANDENBERG, E.; NUNES, M. H.; CARVALHO, D. A. Florestas Inundáveis: Ecologia, Florística e Adaptações das espécies. Lavras: Editora UFLA, 2012.

SOARES, L. R.; FERRER, R. S. Estrutura do componente arbóreo em uma área de floresta ribeirinha na bacia do rio Piratini, Rio Grande do Sul, Brasil. Biotemas, Florianópolis, v. 22, n. 3, p. 47-55, 2009.

SOBRAL, M.; JARENKOW, J. A.; BRACK, P.; IRGANG, B.; LAROCCA, J.; RODRIGUES, R. S. Flora arbórea e arborescente do Rio Grande do Sul, Brasil. São Carlos: RiMA/Novo Ambiente, 2006.

STRECK, E. V.; KÄMPF, N.; DALMOLIN, R. S. D.; KLAMT, E.; NASCIMENTO, P. C.; SCHNEIDER, P.; GIASSON, E.; PINTO, L. F. S. Solos do Rio Grande do Sul. Porto Alegre: EMATER/RS-ASCAR, 2008.

TROPICOS.ORG. Missouri Botanical Garden. Disponíve em: 〈http://www.tropicos.org>. Acesso em: 04 de mar. de 2014. 